\title{
AS RELAÇõES PÚBLICAS E A PROMOÇÃO DE BENS CULTURAIS
}

\author{
Natália dos Santos Gonzales, Caroline Kraus Luvizotto
}

Universidade Estadual Paulista - UNESP, Faculdade de Arquitetura, Artes e Comunicação - FAAC. Programa de Pós-Graduação em Comunicação. Bauru/SP. E-mail: nataliagonzales.rp@gmail.com

\section{RESUMO:}

O olhar do comunicólogo e a prática da Comunicação podem otimizar o processo de acesso e participação da sociedade a bens culturais, a fim de que os cidadãos exerçam seus direitos. Este artigo discute o papel do profissional de Relações Públicas na divulgação e promoção de bens culturais. Todo o esforço feito para que as políticas culturais sejam realizadas de forma eficaz, parte da premissa em que o cidadão tem o direito de possuir informação e de se expressar. Com isso, o foco do profissional de Relações Públicas em um planejamento pode ser também proporcionar ao público de dado programa a participação em sua elaboração. As Relações Públicas atuam de modo imperativo na instituição de políticas públicas, uma vez que podem indicar políticas sociais que envolvam seus diferentes públicos, possibilitando a construção de agentes transformadores da sociedade.

Palavras-chave: Relações Públicas, Políticas Culturais, Comunicação Pública, Bens Culturais.

\section{PUBLIC RELATIONS AND PROMOTE OF CULTURAL GOODS}

\begin{abstract}
:
The look of the communication specialist and practice of communication can optimize the process of access and participation of society to cultural goods in order that citizens exercise their rights. This article discusses the role of the professional Public Relations in the dissemination and promotion of cultural goods. Every effort made to that cultural policies are carried out effectively assumes that the citizen has the right to own information and to express themselves. Thus, the focus of professional public relations in planning can also provide the public with data program to take part in its elaboration. Public relations work imperatively in public policy institution, since it can indicate social policies involving its stakeholders, enabling the construction of agents of change in society.
\end{abstract}

Keywords: Public Relations, Cultural Policies, Public Communication, Cultural Goods. 


\section{INTRODUÇÃO}

Nas últimas décadas, principalmente com o fim da ditadura militar no Brasil, vários setores governamentais que cuidavam especificamente de políticas públicas de certas áreas foram reorganizados. Uma das áreas de atuação de políticas públicas que sofreu mudanças é a área cultural. No Brasil, encontra-se em curso um Plano Nacional de Cultura (PNC), descrito como "um plano de estratégias e diretrizes para a execução de políticas públicas dedicadas à cultura" (BRASIL, 2007, p. 6). "É um mecanismo de planejamento para médio e longo prazo, propulsor de um esforço coletivo para assegurar os direitos culturais aos brasileiros" (p. 11).

Com a evolução dessas políticas adotadas pelo governo, propõe-se a reflexão sobre o conceito de política cultural. Pode-se dizer que uma política cultural ocorre quando há planejamento e existe um projeto duradouro e não somente eventual no campo da cultura, além de não ter o caráter apenas de entretenimento. Para Simis (2007, p. 3) o papel do Estado neste contexto "não é produzir cultura, dizer o que ela deve ser, dirigi-la, conduzi-la, mas sim formular políticas públicas de cultura que a tornem acessível, divulgando-a, fomentando-a, como também políticas de cultura que possam prover meios de produzi-la".

A Comunicação, principalmente a Comunicação Pública, figura como elemento importante neste contexto e exerce papel decisivo em diversas políticas públicas. O Estado desenvolve a Comunicação em meios diversos a fim de atingir os diferentes públicos de seu interesse, deste modo, o olhar do comunicólogo e a prática da Comunicação podem otimizar o processo de acesso e participação da sociedade a bens culturais, a fim de que os cidadãos exerçam seus direitos. $A$ Relações Públicas é a área de atuação onde se concretiza a prática da Comunicação.

De acordo com Brandão (2007, p. 31) a Comunicação Pública pode ser considerada como um "processo de comunicação que se instaura na esfera pública entre o Estado, o Governo e a Sociedade e que se propõe a ser um espaço privilegiado de negociação entre os interesses das diversas instâncias de poder constitutivas da vida pública do pais". Deve atender ao interesse público e garantir a transparência, baseada no direito à informação, direito fundamental do cidadão.

Neste sentido, este artigo discute sobre o papel do profissional de Relações Públicas na divulgação e promoção de bens culturais. Como subsídio para análise dos dados apresentamos um histórico das Relações Públicas no Brasil, para delimitar o campo de atuação e finalmente, apresentamos uma reflexão sobre o papel do Relações Públicas na promoção de bens culturais, sistematizando a sua prática.

\section{RELAÇõES PÚBLICAS, COMUNICAÇÃO E CULTURA}

De acordo com Andrade (1973), as primeiras atribuições da função das Relações Públicas no Brasil ocorreram no dia 30 de janeiro de 1914. Pela primeira vez no país criou-se um departamento com a denominação de Relações Públicas. Essa criação deu-se pela "The Light and Power Co. Ltda.", concessionária da iluminação pública e do transporte coletivo na capital paulista, conhecida durante muitos anos como "Light", uma companhia canadense estabelecida no Brasil no Século XIX.

No campo governamental, a primeira manifestação do aparecimento das Relações Públicas é indicada pela reorganização do Serviço de Publicidade Agrícola do Ministério da Agricultura e sua transformação em Serviço de Informação Agrícola (Decreto-Lei no 2.094, de 28 de março de 1940).

A partir da década de 50, ocorreu o alavanque da profissão Relações Públicas devido à conjuntura de valorização da comunicação com a democratização após a ditadura Varguista, a industrialização - com destaque ao governo desenvolvimentista de Juscelino Kubitschek - e com a chegada de empresas multinacionais e o advento do rádio.

Durante a década de 60 surgiram as primeiras faculdades de Relações Públicas, como a introduzida pela Escola de Comunicação e Artes (ECA) da USP em 1967. Nesta mesma década foi 
emitida a regulamentação da profissão, que tornou a atividade exclusiva dos bacharéis de comunicação social com habilitação em Relações Públicas. O Brasil foi o primeiro país do mundo a deter tal regulamentação. Foi também nesta década que o país entrou no período da ditadura militar. O sistema ditatorial contribuiu com uma forte influência na carreira, uma vez que, no campo profissional houve relativo aumento de trabalho - com destaque ao setor propagandista governamental - no entanto, ocorreu também certa deterioração do ponto de vista político, através da vinculação da área com o regime ditatorial. Foi nesta década também que ocorreu a IV Conferência Interamericana de Relações Públicas, na qual fica definido oficialmente o conceito da profissão. As Relações Públicas podem ser entendidas como "o esforço deliberado, planificado, coeso e contínuo da alta administração, para estabelecer e manter uma compreensão mútua entre uma organização, pública ou privada, e seu pessoal assim como entre essa organização e todos os grupos aos quais está ligada" de modo direto ou indireto (ANDRADE, 1996, p. 105).

A década de 70 caracterizou-se pela grande implantação de faculdades e de departamentos de comunicação. A grande maioria dos cursos pautava-se pelos padrões dos cursos de jornalismo, mas ainda assim, surgiram no país as primeiras traduções de bibliografias estrangeiras e foram editadas as primeiras obras nacionais sobre a área de Relações Públicas. Ainda nesta década, foram criados o Conselho Federal e os Conselhos Regionais de Profissionais de Relações Públicas.

Segundo Andrade (1973), a década de 90 foi marcada pela conscientização das escolas e dos profissionais de Relações Públicas, que possibilitou o combate à decadência da área e passou a agir por uma redefinição do papel da profissão na sociedade, frente ao crescimento das áreas de jornalismo, publicidade e propaganda e marketing. Os órgãos da classe se fortaleceram e em 1994 foi constituído um parlamento nacional para tratar do futuro da profissão. Por falta de demanda e, em alguns casos, de qualificação do corpo docente, muitos cursos superiores de Relações Públicas foram suspensos. Aos demais, coube assumir uma nova postura - a Escola de Comunicação e Artes da USP, por exemplo, firmou em 1994 um acordo de cooperação com a Associação Brasileira das Empresas de Relações Públicas (ABERP).

Baseando-se na premissa básica da atuação de Relações Públicas como sendo a compreensão da comunicação entre organização e seus diferentes públicos; pode-se considerar a atuação do profissional em diversos âmbitos: assessoria de imprensa, gestão de crises, marketing digital, comunicação institucional, endomarketing, produção de eventos, entre outras. Observa-se, portanto, que esse profissional pode atuar de modo eficiente na promoção de bens culturais.

\section{PROMOÇÃO DE BENS CULTURAIS}

Políticas culturais são construídas para cidadãos, para isso há a necessidade de estudos específicos do público em questão para que haja interação e comunicação eficaz entre as partes que estão inseridas nesse processo. Além disso, para executar uma política cultural, há a necessidade de recursos humanos, financeiros e materiais. Levando isso em consideração, vê-se a importância do profissional de relações públicas agir nessa área, utilizando-se do planejamento para direcionar políticas culturais de acordo com o contexto em que estão inseridas.

De acordo com Cesca (1997) planejamento é um processo desenvolvido para alcance de uma situação desejada de um modo eficiente, eficaz e efetivo com o maior aproveitamento de esforços e recursos disponíveis. Corresponde a um conjunto de providências a serem tomadas para promoção de um futuro diferente do passado, em torno de variáveis possíveis de serem atacadas pela organização planejadora.

O planejamento consiste em um método de aplicação, contínuo e permanente, designado a resolver problemas que afetam uma sociedade situada em dado espaço, em determinada época, por meio de uma previsão ordenada capaz de antecipar suas conseqüências. 
O profissional de Relações Públicas está apto para desenvolver estudos a fim de elaborar um planejamento que contemple os objetivos propostos por dada organização. Para ações na área da cultura, não é diferente; porém quando trata-se dessa temática, há a necessidade de estudos mais aprofundados na região em que será aplicada tal política, já que cada localidade possui suas singularidades, em que haverá um público diferente de outra localidade que receberá as informações de maneiras diferentes.

Mesmo com estudos na área de práticas culturais, muitas políticas ainda se fundamentam somente em oferecer obras e atividades artísticas, sem considerar as singularidades e particularidades de todo um processo de consumo cultural. Segundo Botelho e Oliveira (2010), em meados dos anos 1960, estudos pesquisaram sobre a dinâmica envolvida no consumo de obras de arte. Nesse estudo, eles mostraram que os diferentes grupos sociais possuem sistemas de valores e de atitudes culturais cuja transmissão entre as gerações é influenciada pelo ambiente familiar e pela educação formal.

Nessa linha, não há estudos que aliam de fato a teoria com a prática, desse modo, grande parte das instituições continuam apostando na oferta de atividades e bens, sabendo que o contato pontual com determinada atividade artística não diversifica necessariamente os hábitos culturais dessas populações, sendo apenas uma atividade de entretenimento para os freqüentadores. Botelho e Oliveira (2010) citam como exemplo os projetos que oferecem shows, concertos ou peças teatrais a preços módicos, todos em nome da "formação de público". Mas na verdade, o público majoritário desses projetos são aqueles que já são consumidores desses gêneros e não procuram ampliar a composição social do conjunto de freqüentadores.

Além desse fato, outro motivo que auxilia no não cumprimento dos objetivos das políticas de democratização cultural, é o fato de levarem em conta o indivíduo apenas como público (consumidor) e não como um possível participante ativo da vida cultural (ator e propagador).

Segundo as autoras, uma das maneiras de contribuir para que a formação dos públicos seja mais efetiva, é por meio da experiência vivida pelos indivíduos, ou seja, ter a possibilidade de fazer - dança, teatro, música. Com a incorporação desse tipo de experiência na formação dos indivíduos, tem-se uma chance maior de disseminar essas linguagens e seus códigos, a fim de provocar uma alteração verdadeira na relação entre os indivíduos com a cultura e a arte. Desse modo, é possível que a atividade passe de somente uma prática de entretenimento para uma prática na qual este se desdobra num processo de desenvolvimento pessoal.

O gosto do indivíduo é trabalhado, por meio de uma aprendizagem que contém códigos, normas, a evolução e a história dessas linguagens. Dificilmente alguém se impressiona, pela primeira vez, diante de uma obra de arte contemporânea. Há a necessidade de identificar e compreender alguns códigos para que possa existir um diálogo com a arte sugerida.

Alguns projetos procuram levar a cultura erudita para certas populações menos favorecidas, porém não pensam em como essas pessoas irão receber tal arte, nem mesmo como elas poderiam inserir tais experiências em seu cotidiano a fim de tornar esses indivíduos fiéis àquela determinada arte.

O principal objetivo buscado pelas autoras é de trazer como prioritário a questão da formação de públicos, em que a "democratização" de linguagens é imprescindível para que se pense em diferentes formas que diferentes públicos podem se identificar e apropriar os códigos envolvidos na manifestação em questão. Além de incentivar que os formuladores de políticas, projetos não se contentem em apenas oferecer a oportunidade para a população, sem levar em consideração as singularidades presentes em cada uma delas. Com isso, há uma acepção ampla do termo acesso que inclui o acesso social, o acesso a códigos, e não somente a oferta e a gratuidade dos produtos culturais, contribuindo para que os indivíduos possam construir seu desenvolvimento pessoal. 
De acordo com Botelho e Oliveira (2010), pensar as várias modalidades de mediação cultural é algo imprescindível por parte das instituições, desde a escolar até organizações como centros culturais ou museus. A educação formal é certamente a primeira a ser lembrada, mesmo porque muitas pesquisas mostram a efetiva correlação entre o nível educacional e as práticas culturais dos indivíduos. Além desse elemento, há também a educação informal, especialmente via experiências de sociabilidade e lazer. Levar em conta a formação dos públicos como um todo é o que pode alterar os padrões de relação com as diversas expressões artísticas.

Segundo Botelho e Oliveira (2010), há pesquisas que indicam que a vivência de situações de sociabilidade pode abrir caminhos para que um indivíduo possa consumir determinadas manifestações culturais, numa lógica contrária a de que o caminho visto como o único possível seria o "gosto" precedendo e motivando toda e qualquer prática cultural. Os gestores dessas instituições podem funcionar como formadores e mediadores fundamentais, se desenvolverem uma eficaz política de relacionamento com seus públicos. Se há uma boa política de relacionamento com o público, os freqüentadores se sentirão mais íntimos do local e mais receptivos com as atividades da instituição. Para realização dessa atividade, é necessária a existência de um setor que faça análise e estudos dos públicos para direcionar as ações realizadas por dada instituição.

Atualmente no Brasil, pouco se faz em relação à tentativa de expandir o envolvimento dos diversos públicos com a cultura. Porém, o que se faz nesse sentido é feito de maneira desarticulada de uma visão mais abrangente, incapaz de dimensionar necessidades no tempo e no espaço e de articulá-las.

Utilizando-se de ferramentas de relações públicas, tais como modelos de planejamento estratégico, de avaliação de públicos, de pesquisas quanti e qualitativas, esse quadro pode ser melhorado. Uma das fases de um planejamento é a mensuração/avaliação de determinada ação/projeto.

Segundo Castanhar e Costa (2003), historicamente, na administração pública brasileira não há a preocupação de avaliar programas públicos, em geral, e programas sociais, em particular. A produção de conhecimento técnico na busca da melhoria no gerenciamento do setor público sempre esteve relacionada aos processos de formulação de programas do que para os relacionados a sua implementação e avaliação.

De acordo com os autores, há evidências de que esse desinteresse pela avaliação dos programas está diminuindo. Essa mudança decorre de transformações ocorridas na sociedade e no Estado brasileiro a partir dos meados de 1980 até os dias atuais. Com a crise da dívida externa, nos anos 1980, e a interrupção de um longo crescimento econômico, houve uma alta na desigualdade social no país. O âmbito econômico desfavorável no Brasil, acarretou em um crescimento da demanda por ações e projetos na área social.

Castanhar e Costa (2003) apontam que o objetivo do funcionamento do Estado é fazê-lo funcionar melhor, com custos menores. Para isso, utilizam-se da avaliação do desempenho dos programas públicos a fim de avaliar a performance. Vale lembrar que quando o poder público terceiriza certos serviços para agências autônomas ou empresas privadas, a necessidade de avaliação torna-se ainda maior. Com isso, a avaliação de resultados passa a ser peça fundamental para a reforma do Estado.

De acordo com Castanhar e Costa (2003), o grande desafio para a disseminação da prática da avaliação de projetos no setor público é encontrar formas ágeis e de baixo custo de mensurar o desempenho e fornecer informações úteis ao responsável pela gestão dos programas sociais, além da necessidade de correções, alterações, ou até mesmo a inviabilidade do projeto. 0 objetivo básico do processo é melhorar os resultados de determinado projeto/programa, e não somente produzir números. É importante realizar a análise dos dados coletados a fim de realizar a gestão da avaliação. 
Nessa fase, não se pode deixar com que dificuldades durante o processo de avaliação criem obstáculos que não permitam a continuidade da análise. O profissional de Relações Públicas é capaz de gerir essa avaliação de acordo com a direção dada inicialmente com a delimitação de objetivos, estudos de públicos. Para isso, seria necessário um estudo aprofundado de que públicos deseja atingir, para assim, o profissional delimitar estratégias para cada tipo de público, assegurando que as ações poderão ser mensuradas e avaliadas para ter um projeto contínuo e sujeito à alterações e adaptações de acordo com o decorrer das atividades.

\section{CONSIDERAÇÕES FINAIS}

As Relações Públicas desempenham um papel muito além da Comunicação. Ela é fundamental para o equilíbrio nas relações sociais entre organizações, sejam elas públicas, privadas ou não governamentais, e seus públicos, os cidadãos. Atuam de modo imperativo na instituição de políticas públicas, uma vez que podem indicar políticas sociais que envolvam seus diferentes públicos, possibilitando a construção de agentes transformadores da sociedade.

Todo o esforço feito para que as políticas culturais sejam realizadas de forma eficaz, parte da premissa em que o cidadão tem o direito de possuir informação e de se expressar. Com isso, o foco do profissional de Relações Públicas em um planejamento pode ser também proporcionar ao público de dado programa a participação em sua elaboração.

O objetivo da Comunicação passa dos interesses da organização para os interesses do conjunto da sociedade e, assim, o planejamento muda as ações e estratégias de comunicação, em conjugação, precisam ser repensadas e, consequentemente, melhor direcionadas.

Nesse contexto, passa-se das reflexões teóricas à necessidade de implementação dos ideais e dos princípios da Comunicação Pública no cotidiano das organizações. O primeiro passo seria construir uma cultura de relacionamento, na qual os cidadãos se entendam como sujeitos comunicantes e participantes do processo de Comunicação Pública e em um dado planejamento. Também é preciso construir estratégicas de diálogo que objetivem o interesse público, de forma que o que foi debatido ultrapasse os limites somente do diálogo e, posteriormente, se transforme em políticas públicas efetivas e eficazes.

\section{REFERÊNCIAS BIBLIOGRÁFICAS}

ANDRADE, C. T. S. Panorama histórico de relações públicas. 2a ed. São Paulo: Com-Arte, 1973. . Dicionário profissional de relações públicas e comunicação. São Paulo: Summus, 1996.

BOTELHO, I.; OLIVEIRA, C. V. Centros culturais e a formação de novos públicos. Percepções - Cinco questões sobre políticas culturais. São Paulo: Itaú Cultural, 2010.

BRANDÃO, E. P. Conceito de comunicação pública. In: DUARTE, J. (Org.). Comunicação Pública: estado, mercado, sociedade e interesse público. São Paulo: Atlas, 2007. p. 10 - 14.

BRASIL. MINISTÉRIO DA CULTURA. Plano Nacional de Cultura: Diretrizes Gerais. 1ạ Edição. Brasília: Ministério da Cultura, 2007a. Disponível em

<http://www.cultura.gov.br/site/?p=9356>. Acesso em 9 agosto de 2011.

CASTANHAR, J. C.; COSTA, J. C. Avaliação de programas públicos: desafios conceituais e metodológicos. Revista de Administração Pública (RAP), Edição Set/Out, Rio de Janeiro, 2003.

CESCA, C. G. G. Organização de Eventos: Manual para planejamento e execução. São Paulo: Summus, 1997. 
SIMIS. A. Política Cultural como Política Pública. In. III ENECULT - Encontro de Estudos Multidisciplinares em Cultura. Anais do III ENECULT. Faculdade de Comunicação / UFBa, SalvadorBahia-Brasil. 2007. 